\title{
Sistem Informasi Program Kreativitas Mahasiswa berbasis Web Service dan Microservice
}

\author{
Poetri Lestari Lokapitasari Belluano a,1,*, Purnawansyah Purnawansyah a,2, Benny Leonard Enrico \\ Panggabean ${ }^{\mathrm{a}, 3}$ dan Herman Herman ${ }^{\mathrm{a}, 4}$ \\ ${ }^{a}$ Universitas Muslim Indonesia, Urip Sumohardjo Km.05 Kampus II UMI, Makassar, 90231, Indonesia \\ Ipoetrilestari@umi.ac.id; ${ }^{2}$ purnawansyah@umi.ac.id; ${ }^{3}$ bendo01@gmail.com; ${ }^{4}$ herman@umi.ac.id \\ * corresponding author
}

\section{INFORMASI ARTIKEL}

Dikirim: 6 Maret 2020

Diulas: 7 April 2020

Direvisi: 9 April 2020

Diterbitkan: 27 April 2020

\section{Kata Kunci:}

Sistem Informasi

PKM

Web Service

Microservice

\section{ABSTRAK}

Sistem informasi dihadapkan pada pengembangan yang signifikan, seketika dituntut perlu ada perubahan kebijakan ataupun penambahan fitur-fitur sebagai upaya pemeliharaan sesuai kebutuhan business rule baik internal maupun eksternal sistem. Penelitian ini bertujuan membentuk infrastruktur microservice untuk pemeliharaan perubahan alur proses bisnis pada pengembangan sistem informasi. Metode penelitian meliputi studi lapangan dan kepustakaan sehubungan pokok pembahasan terkait program kreativitas mahasiswa (PKM), Sistem Informasi, Web Service, Microservice. Perancangan sistem informasi dan basis data menggunakan paradigma Convention Over Configuration. Tahap perancangan menggunakan model Prototyping untuk merepresentasikan secara grafis alur kerja sistem. Sedangkan untuk pemodelan sistem memanfaatkan tools Unified Modeling Language (UML). Pengelolaan aplikasi Data Base Management System (DBMS) menggunakan GORM, Go Validator sebagai alat validasi data, dan Gorilla Mux sebagai rooter REST. Aplikasi berjalan menggunakan Advanced Message Queuing protocol. Luaran dari implementasi pengembangan sistem informasi internal universitas berbasis web service dengan arsitektur microservice untuk pelaporan kegiatan PKM, dimana hubungan antar unit dalam transaksi data (publish, deliver auto ack) dilaksanakan dengan durasi waku $0.00 /$ second.

\section{Keywords:}

Information System

PKM

Web service

Microservice

\section{ABSTRACT}

The information system is faced with a significant development, it needs to have not only the policy changes but also the features as an effort update, according to necessity both internal and external business rule systems. This research aims to form a microservice infrastructure for updating changes in flow of business process to the development of information systems.This Research methods come under both field studies and literature to the subject matter related with the development of Information Systems in managing data of program kreativitas mahasiswa (PKM), Web services and Microservice Architecture. The design is using Prototype model to represent graphically the workflow of the system Model which is using the Unified Modeling Language (UML) tool, Managing the Data Base Management System (DBMS) application using GORM, Go Validator as a data validation tool, and Gorilla Mux as the REST rooter. The application runs by utilizing the Advanced Message Queuing protocol.In conclusion, the implementation of web servicebased university internal information system development with microservice architecture for PKM is reporting activities in where the relationship between units in data transactions (publish, send automatically) is carried out with a duration of time $0,00 / \mathrm{sec}$.

This is an open access article under the CC-BY-SA license. 


\section{Pendahuluan}

Saat ini sistem informasi [1][2] dihadapkan pada pengembagan yang signifikan, dimana seketika dituntut perlu ada perubahan-perubahan kebijakan ataupun penambahan fitur-fitur sesuai kebutuhan business rule [3] baik internal maupun eksternal sistem. Semisal ketika suatu sistem informasi yang telah berjalan lalu perlu dilakukan pengembangan modul ataupun fitur tertentu untuk menyesuaikan kebutuhan dan kebijakan internal seperti perlu adanya fitur pengolahan data program kreativitas mahasiswa (PKM), maka proses penambahan fitur tersebut dalam pengembangan business rules akademik diharapkan tidak mengganggu kinerja dari proses sistem yang sudah berjalan. Oleh karenanya dibutuhkanlah pengembangan aplikasi sistem pengelolaan data yang mampu terhubung dan berkomunikasi secara real-time dan otomatis dalam lingkup akademik, untuk mendukung kinerja program studi, fakultas, dan perguruan tinggi agar dapat secara konsisten melaksanakan pelaporan akademik. Tidak cukup hanya menerapkan aplikasi berbasis Web dengan desain Antarmuka Pengguna (User Interface) sebagai perangkat virtual semata-mata dan sulit dimodifikasi. Pola arsitektur monolitik aplikasi web akan sulit dipahami dan dimodifikasi, dimana sebuah kesalahan pada modul dapat mematikan seluruh proses karena setiap modul dijalankan pada proses yang sama yang bersifat single apps dan single database[4].

Dalam pengembangan Sistem Informasi Akademik[5] perlu menggunakan metode web service RESTful yang menggunakan fitur protocol HTTP untuk mendukung komunikasi dengan sistem lain yang berbeda platform[6]. Sistem informasi menggunakan web service mampu melaksanakan pertukaran data/informasi melalui bermacam-macam jalur komunikasi dengan berbagai ragam sistem untuk bekerja sama dan berinteraksi dengan aplikasi lainnya[7][8][9]. Kebutuhan modifikasi fitur atau fungsi modul Sistem Informasi menjadi lebih besar, seperti penambahan fitur program kreativitas mahasiswa (PKM) yang membutuhkan pengolahan data pada platform yang berbeda domain sistem, menuntut pengembangan teknologi webservice agar melaksanakan pemeliharaan domain bisnis ketika terjadi perubahan atau penambahan proses bisnis tanpa mempengaruhi kinerja sistem informasi secara keseluruhan.

Hal tersebut akan didukung dengan pengembangan sistem informasi menggunakan web service dengan konsep infrastruktur microservice[10] yakni sistem informasi dengan model arsitektur yang menyatukan aplikasi sebagai kumpulan layanan yang digabungkan secara fleksibel[11] sesuai penerapan business rule. Arsitektur microservice memungkinkan pengiriman / penyebaran aplikasi besar dan kompleks secara terusmenerus sehingga memungkinkan suatu organisasi untuk mengembangkan sistem dengan berbagai teknologi yang berbeda-beda[12][13][10]. Sebagai prototipe menggunakan implementasi dari aplikasi xSIA PKM yang mengelola sistem informasi Program Kreativitas Mahasiswa (PKM). Aplikasi tersebut dikembangkan dengan tujuan menyediakan layanan informasi dalam bentuk website dimana antar sistem dapat berinteraksi melalui layanan web service, sebagai upaya pemeliharaan saat tejadi perubahan alur proses bisnis pada pengembangan sistem informasi.

\section{Metode}

Penelitian dilaksanakan mengadopsi System Development Life Cycle yang disederhanakan dengan tahapan sebagai beikut:

1. Identifikasi Masalah dengan menguraikan permasalahan yang ditemui khususnya untuk aplikasi yang dimiliki oleh Fakultas Ilmu Komputer UMI dan Sistem Informasi Akademik

2. Pengumpulan Data diantaranya data akademik mahasiswa dan data kegiatan kreativitas mahasiswa. Populasi data akademik yang digunakan sebagai sample bersumber dari transaksi akademik periode tahun 2018.

3. Analisis Kebutuhan yakni pembuatan analisa aliran kerja sistem yang sedang berjalan untuk disesuaikan dengan model sistem yang akan dibangun.

4. Desain Sistem dengan membuat rancangan basis data, arsitektur sistem microservice, dan antarmuka aplikasi xSIA PKM sesuai spesifikasi kebutuhan dari hasil analisis.

5. Pengujian sistem, dilaksanakan setelah aplikasi dibangun dengan menguji microservice unit menggunakan teknik Alpha Testing.

Metode penelitian meliputi studi lapangan dan kepustakaan sehubungan pokok pembahasan terkait program kreativitas mahasiswa (PKM), Sistem Informasi, Webservice, Microservice. Perancangan sistem informasi dan basis data menggunakan paradigma Convention Over Configuration. Tahap perancangan menggunakan model Prototyping untuk merepresentasikan secara grafis alur kerja sistem. Sedangkan untuk pemodelan sistem memanfaatkan tools Unified Modeling Language (UML), Pengelolaan aplikasi Data Base Management System (DBMS)[14] menggunakan GORM, Go Validator sebagai alat validasi data, dan Gorilla Mux sebagai rooter REST. Advanced Message Queuing protocol sebagai media pengiriman pesan dalam komunikasi data secara Asychronous.

Rancangan penelitian eksperimen, didasarkan pada adanya manipulasi variabel bebas meliputi informasi yang akan disajikan bersifat dinamis sehingga pengguna dapat melakukan perubahan data informasi sewaktu-waktu jika diperlukan, dan mengukur efek pada variabel terikatnya. 


\section{Hasil dan Pembahasan}

Microservices membutuhkan dekomposisi fungsional aplikasi dapat dilihat pada Gambar 1, dimana aplikasi monolitik dipecah menjadi beberapa layanan yang lebih kecil, masing-masing ditempatkan di arsipnya sendiri, dan kemudian disusun sebagai satu aplikasi menggunakan komunikasi ringan standar, seperti REST melalui HTTP."[6],[10],[12]".

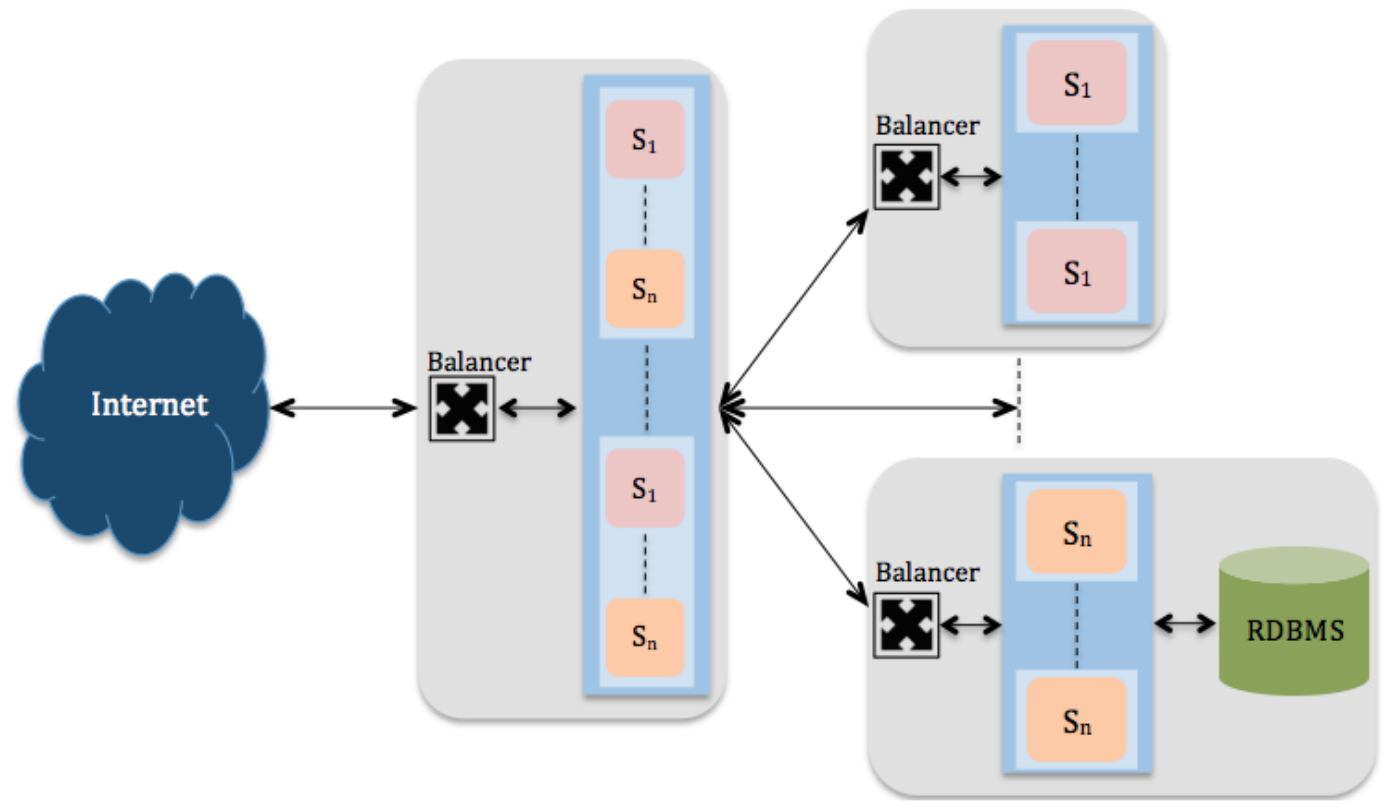

Gambar 1. Tipikal aplikasi berbasis microservice

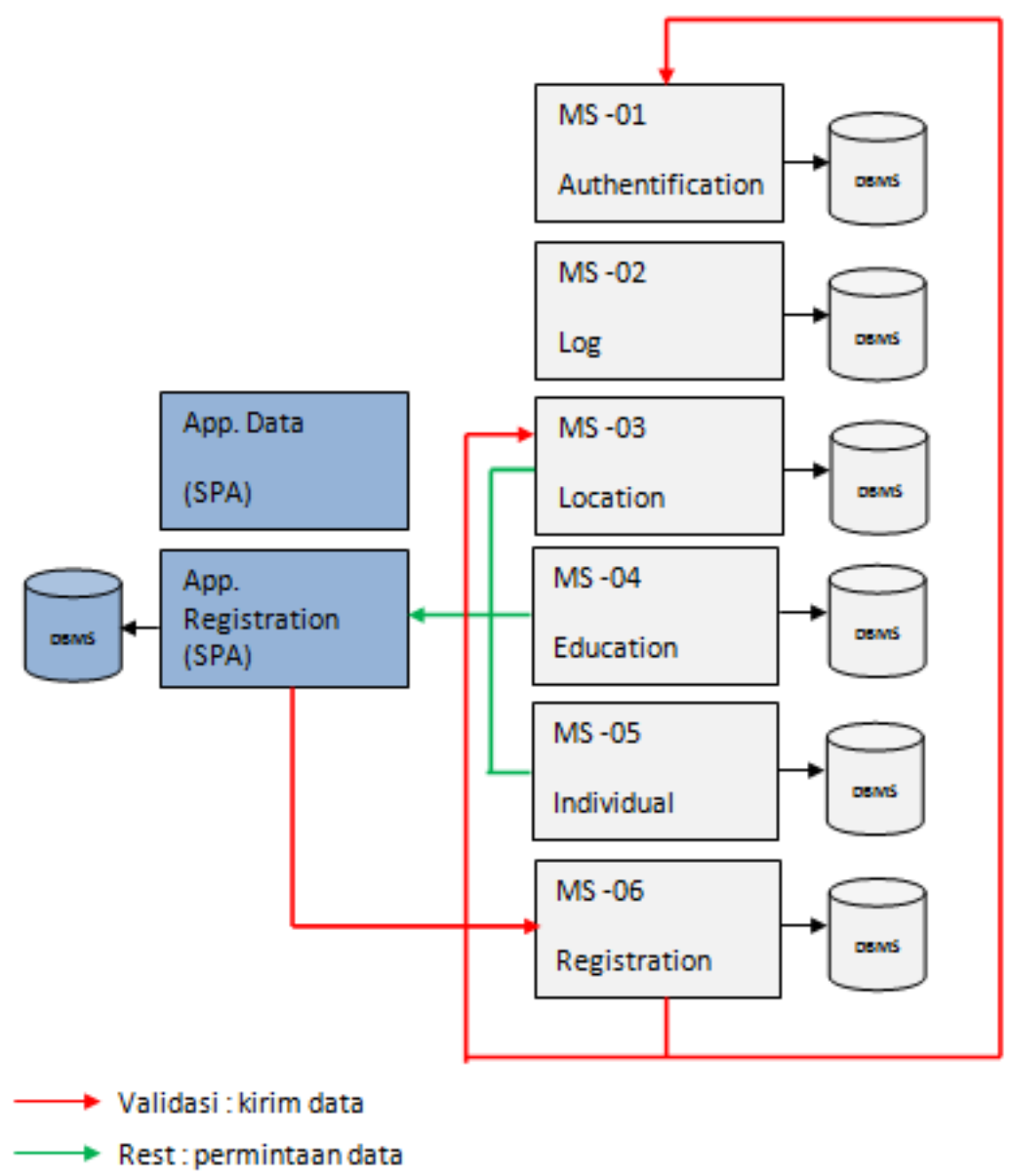

Gambar 2. Rancangan sistem informasi menggunakan microservice 
Gambar 2 menunjukan desain sistem informasi akademik xSIA PKM yang dibangun khusus untuk membantu kebutuhan pengelolaan kegiatan administrasi Program Kreatif Mahasiswa yang masih dijalankan secara semi manual (Software Word Processing ex: word, excell). Sistem Informasi ini juga dapat berkomunikasi dengan aplikasi pelaporan resmi DITJEN - DIKTI melalui fitur web service FEEDER DIKTI. Beberapa fitur yang dimiliki oleh xSIA adalah sebagai berikut:

1. Berjalan pada cloud system based, dimana pengguna tidak perlu menyediakan perangkat keras (Server) dalam pengoperasian sistem ini, hal ini dapat memberikan penjaminan bahwa sistem berjalan setiap saat tanpa menghadapi kendala non teknis seperti listrik padam, keamanan server, biaya operasional yang lebih murah, dan pengaksesan dari dan kapan saja sepanjang pengguna mempunyai koneksi internet

2. Antar muka pengguna lebih mudah dioperasikan, baik dari desktop work station maupun mobile devices (ex: handphone dan tablet).

3. Perbaikan Bug/Error Jarak Jauh (jika ditemukan) akan ditangani dan diperbaiki dengan segera

4. Pengembangan kebutuhan pelaporan PKM disesuaikan dengan aplikasi pelaporan resmi DITJEN DIKTI, sehingga baik secara performansi dan kebutuhan, sistem akan beroperasi dengan optimal[15].

Aplikasi xSIA PKM dengan arsitektur Microservice menggunakan variable data diantaranya master dosen, master mahasiswa, master institusi, master Authentifikasi untuk pengelolaan data PKM. Sedangkan prototype antarmuka yang dirancang terdiri dari:

1) administrator.xsia.app

2) api.person.xsia.app

3) api.institution.xsia.app

4) api.academic.lecture.xsia.app

5) api.academic.student.xsia.app

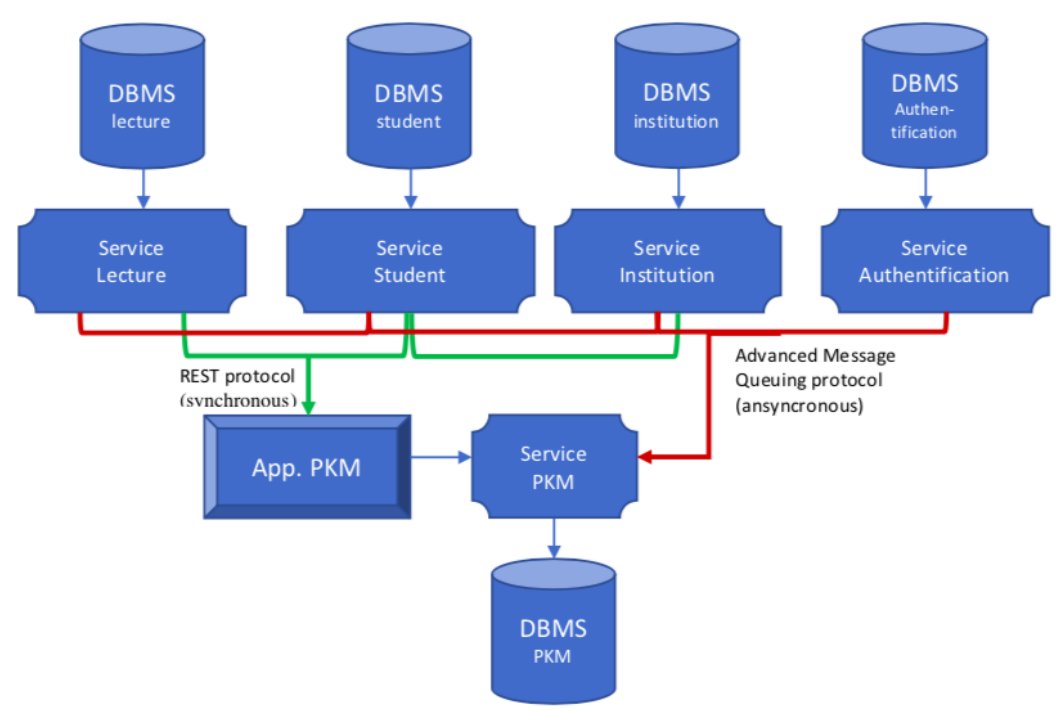

Gambar 3. Arsitektur Microservice xSIA PKM

Gambar 3. menunjukkan arsitektur microservice aplikasi xSIA-PKM dipecah menjadi unit-unit kecil sesuai spesifikasi fungsinya masing-masing dan secara mandiri mengoperasikan layanan (service) tanpa bergantung pada komponen unit lain (loose coupling) sehingga tidak mengganggu kinerja tiap unit ketika terjadi perubahan atau kegagalan proses bisnis pada salah satu unit. REST protocol mengatur request data antara Aplikasi dengan unit microservice secara synchronous, sedangkan Advanced Message Queuing protocol mengatur komunikasi data secara ansyncronous antar unit microservice.

Pada sistem terdapat 2 Actor yang mengakses dan mengelola data informasi yakni Actor User dan Actor Microservice. Kedua actor akan bertukar data sehubungan informasi PKM yang akses dan notifikasi dikontrol dan dimodelkan oleh sistem web service. Actor User melakukan request meminta data daftar peserta PKM ke xSIA PKM Microservice Router yang selanjutnya akan memeriksa authentifikasi Actor User untuk memastikan user dikenali oleh sistem.

Validitas data user untuk aktivias permintaan Request data akan diteruskan oleh controller untuk meminta data yang dimaksud ke masing-masing unit .app yang tersedia di dalam sistem yang menyediakan akses data Authentifikasi, Person, General, dan Location. Seperti yang terlihat pada Gambar 4. 


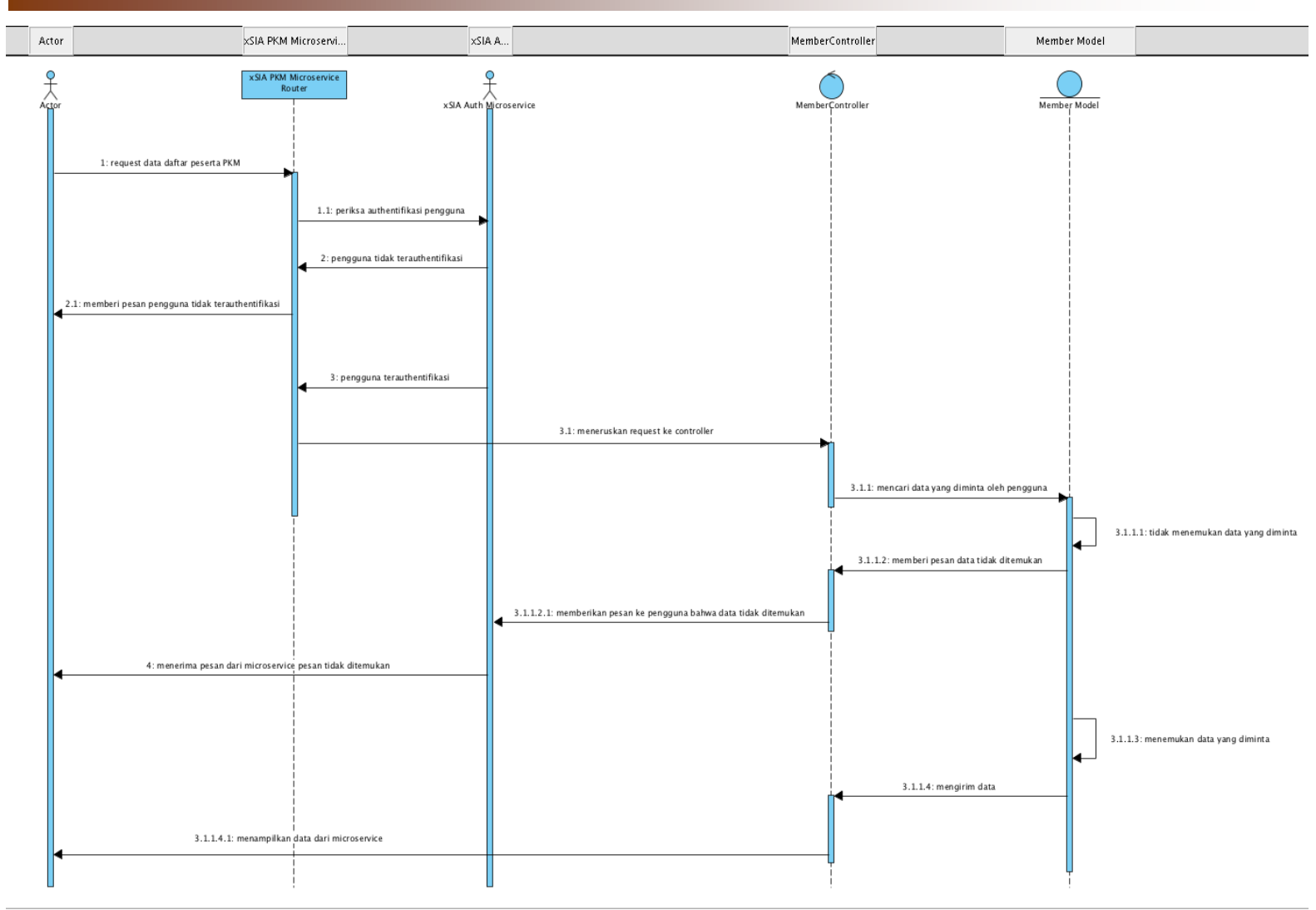

Gambar 4 . Alur sistem xSIA PKM menggunakan microservice

Simulasi antarmuka implementasi sistem informasi PKM menggunakan web service saat terjadi permintaan data menggunakan infrastruktur microservice dalam upaya pemeliharaan struktur sistem ketika terjadi perubahan alur proses bisnis. Berikut interaksi antarmuka yang tersedia pada aplikasi XSIA PKM ;

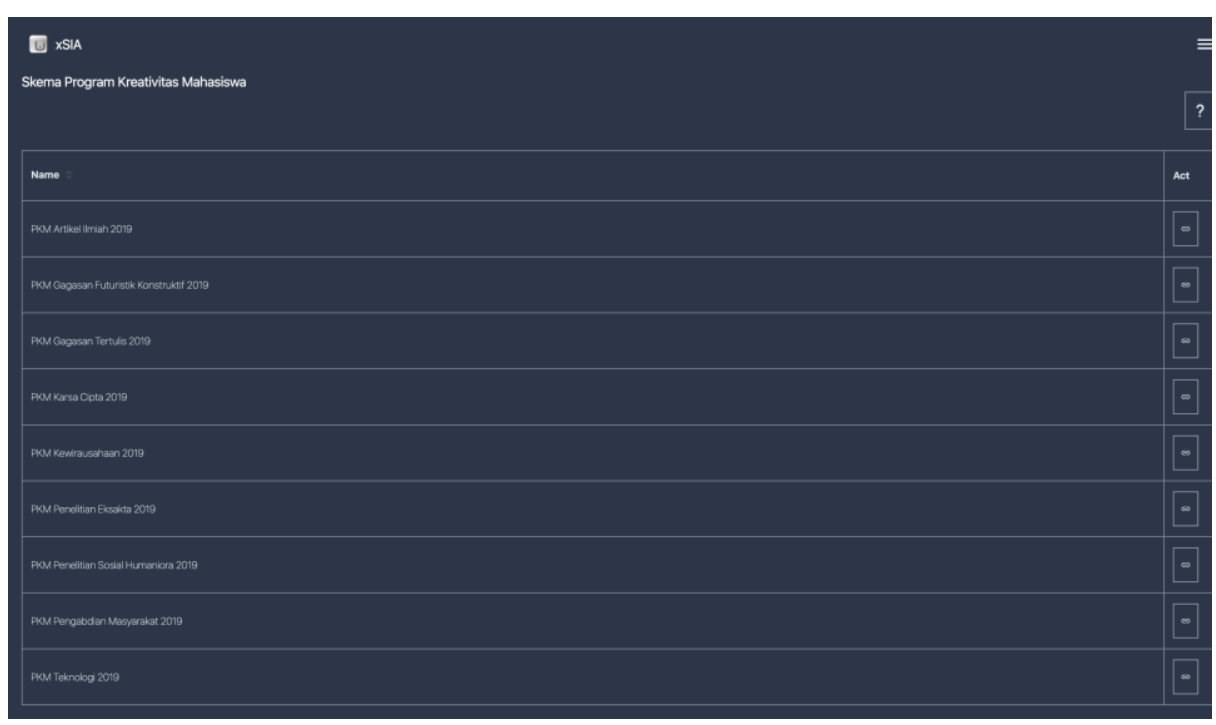

Gambar 5. Pemilihan Skema PKM

Pada Gambar 5 terdapat aksi dimana user memasukkan pilihan kategori skema PKM yang ingin diikuti. Selanjutnya user mengisi seluruh data yang dibutuhkan sehubungan dengan PKM seperti informasi proposisi yang memuat nama tim, jumlah anggota, dan biaya. Terdapat pula uraian umum seperti judul, email, usulan biaya, jangka waktu pelaksanaan, program studi, dosen pembimbing, nama anggota tim, dan unggah dokumen proposal. Setelah mengunggah data proposal, maka file proposal akan diusulkan dan diakses oleh Evaluator yakni tim penilai internal universitas. 
Pengaturan dan penilaian Evaluator diakses langsung oleh tim penilai yang ditunjuk oleh penanggung jawab PKM internal universitas, dimana pada antarmuka telah termuat detail data submission tim PKM yang telah teregistrasi dan siap dinilai oleh Evaluator.

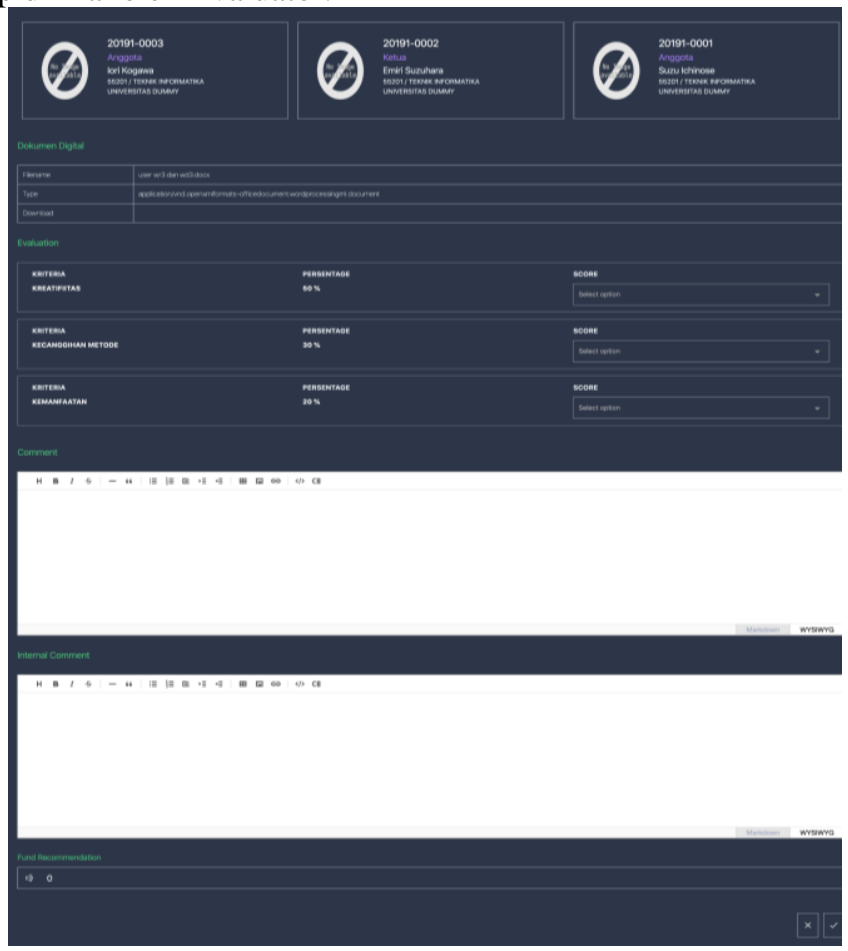

Gambar 6. Penilaian Evaluator

Pada laman Penilaian Evaluator seperti yang terlihat pada Gambar 6 para Evaluator (Tim Penilai) mengisi komponen penilaiannya dengan detail sehingga menjadi acuan Pimpinan internal universitas yang berwenang dapat mengambil keputusan terhadap kelayakan masing-masing tim PKM untuk dilanjutkan ke tahap Submit Proposal ke PDDIKTI.

Aplikasi XSIA PKM yang dirancang sebagai bentuk pengembangan sistem informasi menggunakan web service dengan model arsitektur microservice ini dapat dilihat melalui beberapa tahapan pengujian sistem menggunakan Alpha Testing sebagai berikut :

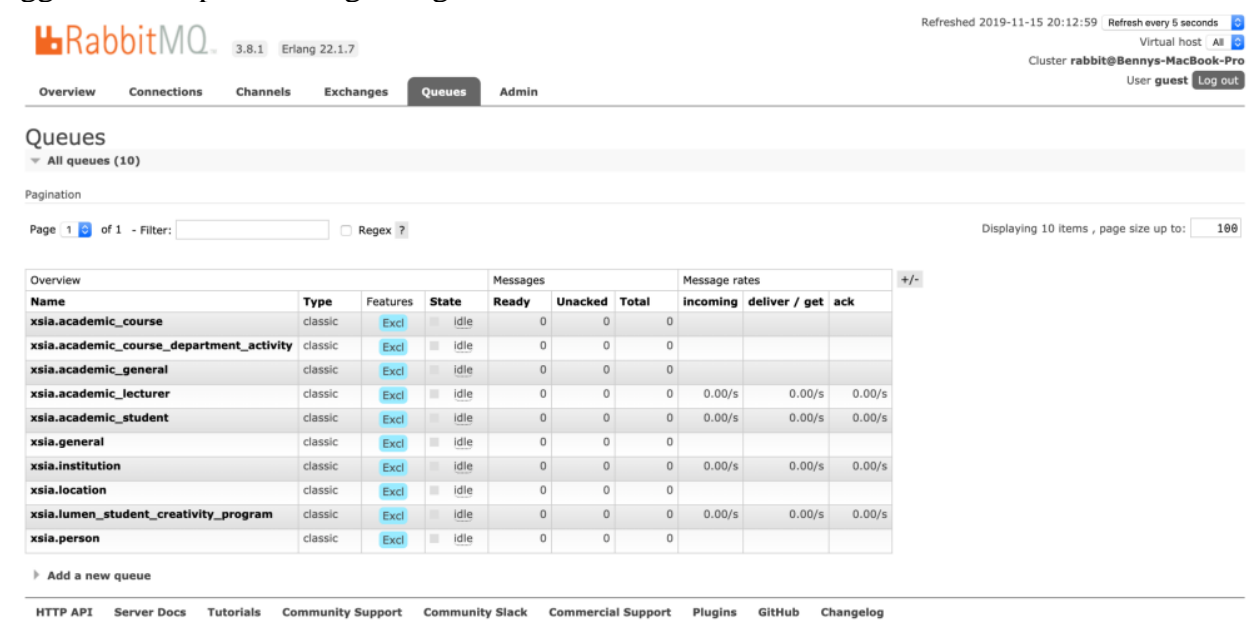

Gambar 7. Implementasi uji unit-unit pada aplikasi PKM

Gambar 7 menunjukkan implementasi Alpha Testing menggunakan RabbitMQ tools dimana telah terjadi pola microservice dalam mengelola komunikasi data antar microservice dalam sistem aplikasi PKM. Dimana terlihat sejumlah unit yang saling berkomunikasi secara Asynchronous (waktu tunda/tunggu). Misalkan terjadi transaksi data pada aplikasi PKM, dimana microservice student (xsia.academin_student) membutuhkan data pada microservice lecturer (xsia.academic_lecturer), maka microservice student akan menghubungi microservice lecturer melalui protocol Advance Message Queuing (AMQ) yang dimiliki melalui tools RabbitMQ. Microservice unit telah sukses berjalan ketika terjadi transaksi seperti terlihat pada 
Gambar 8. Tujuan dari pengembangan sistem informasi menggunakan Web Service Dengan Model Arsitektur Microservice adalah untuk memudahkan komunikasi antar service yang ada dalam website tanpa mengganggu struktur dari aplikasi secara keseluruhan jika terjadi perubahan proses bisnis pada sistem.

\section{$\leftarrow \quad \rightarrow \quad$ C $\quad$ a api.academic.student.xsia.app}

\section{"MS 8305 xSIA Academic Student"}

Gambar 8. Uji unit XSIA academic_student

Simulasi pada web service aplikasi XSIA PKM ditambahkan satu unit Cource (xsia.academic_cource) yang berfungsi sebagai bagian yang mengelola data matakuliah untuk digunakan sebagai pendukung kebutuhan komunikasi ke unit lecture (xsia.academic_lecturer) dalam pengembangan sistem informasi akademik. Gambar 9 adalah antarmuka untuk memasukkan daftar mata kuliah berdasarkan kode matakuliah, nama matakuliah, jumlah sks (bobot sks untuk praktek dan teori), tanggal aktivasi matakuliah, dan sebagainya sehubungan data matakuliah yang dibutuhkan dalam pelaporan akademik.

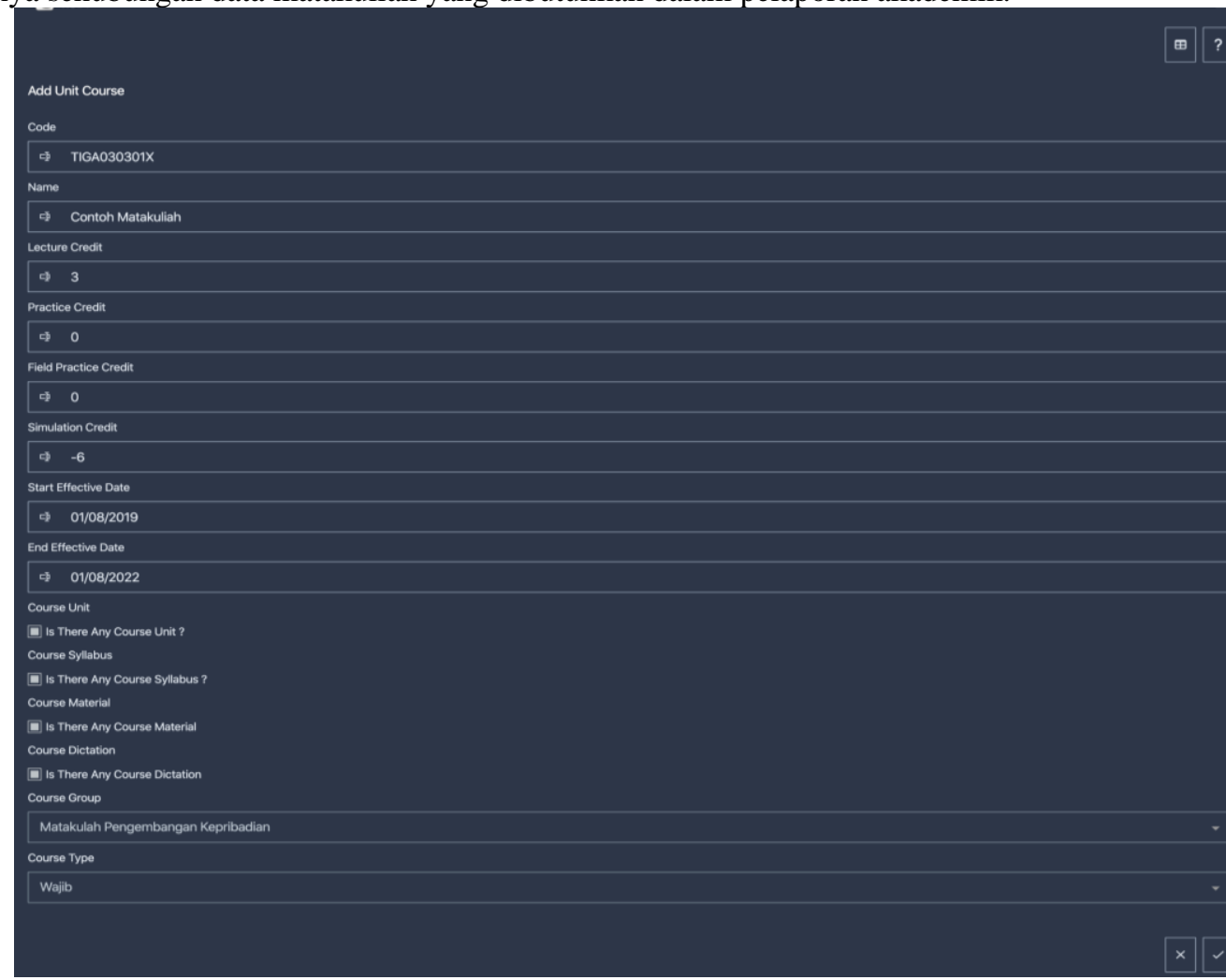

Gambar 9. Antarmuka input data unit cource

Untuk melihat aktivasi unit cource saat dijalankan bersama-sama terhubung dengan unit yang lain dalam aplikasi xSIA PKM menggunakan protocol Advance Message Queuing (AMQ) dilihat seperti Gambar 10 yang memperlihatkan adanya grafik menandakan bahwa microservice telah berjalan dengan sistem web service pada aplikasi xSIA PKM. Dimana hubungan antar unit dalam transaksi data (publish, deliver auto ack) dilaksanakan dengan durasi waku 0.00/second. 


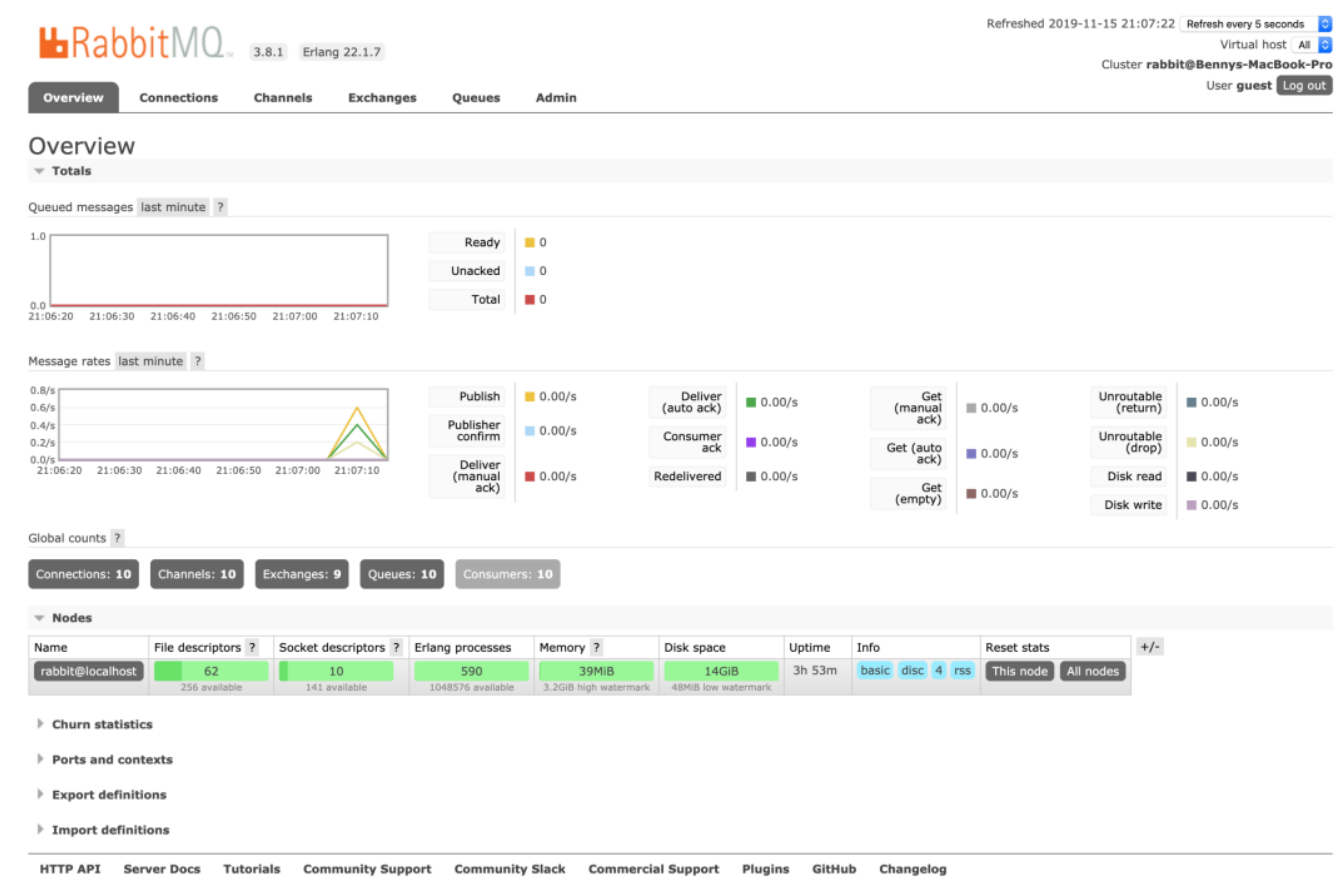

Gambar 10. Uji Aktivasi Unit Cource

\section{Kesimpulan dan saran}

Pengembangan sistem informasi menggunakan web service dengan model arsitektur microservice adalah suatu bentuk aplikasi sistem informasi internal universitas berbasis microservice untuk membantu institusi dalam mengelola pelaporan kegiatan program kreativitas mahasiswa internal berupa aplikasi xSIA PKM yang mampu memelihara infrastruktur sistem aplikasi terhadap perubahan alur proses bisnis yang seketika dapat terjadi dalam lingkup institusi sesuai kebutuhan, kebijakan dan kepentingan internal, tanpa mengganggu jalannya sistem akademik lainnya. Keandalan sistem microservice dapat bekerja maksimal dalam interval waktu 0.00/detik dengan penggunaan sumber daya sistem yang kecil karena komunikasi data diakomodir sesuai kebutuhan unit-unit. Aplikasi berjalan menggunakan Advanced Message Queuing protocol yang mengatur komunikasi data secara asyncronous (waktu tunggu) antar microservice. Sedangkan transaksi data antar unit microservice menggunakan Rest Protocol yang bersifat synchronous dimana data diminta sesuai kebutuhan unit.

Sedangkan untuk dapat memenuhi kebutuhan akan integrasi data secara meluas yakni data dan informasi akademik tidak hanya dapat digunakan pada transaksi internal namun dapat dimanfaatkan pada transaksi eksternal. Serta dapat diimplementasikan pada lebih dari satu unit perangkat secara fleksibel, sehingga Aplikasi xSIA PKM dapat diimplementasikan tepat guna.

\section{Daftar Pustaka}

[1] E. Pertama, C. Pertama, G. Ilmu, and I. Judul, "Pengantar Sistem Informasi" Yogyakarta: Graha Ilmu, 2012.

[2] Ivan Arifard Watung, M. Alicia A. E. Sinsuw, ST., and M. Sary D. E. Paturusi, ST., M.Eng Xaverius B. N. Najoan, ST., "Perancangan Sistem Informasi Data Alumni," J. Ilm. Sist. Manajenmen Inform., vol. 1, no. 1, pp. 47-57, 2014.

[3] S. Alter, "Connecting People, Processes and IT for Business Results," Inf. Syst., 2006.

[4] A. Hermawan, "Peningkatan Ketersediaan Aplikasi Web Menggunakan Arsitektur Layanan Mikro Berdasarkan Identifikasi Log Akses." Thesis, Institut Teknologi Sepuluh Nopember, 2017

[5] E. Yulianto, A. Yani, and Nurajijah, "Sistem Informasi Akademik Penilaian Berbasis Web Pada SMA Mandiri Balaraja - Kab. Tanggerang," J. TECHNO Nusa Mandiri, vol. 15, no. 1, pp. 57-62, 2018.

[6] D. Wijonarko and B. W. R. Mulya, "Pengembangan Antarmuka Pemrograman Aplikasi Menggunakan Metode RESTful pada Sistem Informasi Akademik Politeknik Kota Malang," Smatika J., vol. 8, no. 02, pp. 63-66, 2018, doi: 10.32664/smatika.v8i02.202.

[7] P. L. Lokapitasari Belluano, "Pengembangan Single Page Application Pada Sistem Informasi Akademik," Ilk. J. Ilm., vol. 10, no. 1, pp. 38-43, 2018, doi: 10.33096/ilkom.v10i1.204.38-43.

[8] B. Leonard and E. Panggabean, "Integrasi Pangkalan Data Perguruan Tinggi dengan Teknologi Web Service," 2013. 
[9] P. Purnawansyah and A. Faradibah, "Implementasi Web Service pada Aplikasi Sistem Informasi Akademik dengan Platform Mobile," 2014.

[10] A. Messina, R. Rizzo, P. Storniolo, and A. Urso, "A Simplified Database Pattern for the Microservice Architecture," Eighth Int. Conf. Adv. Databases, Knowledge, Data Appl., no. June, pp. 35-40, 2016, doi: 10.13140/RG.2.1.3529.3681.

[11] P. Hendradi and P. Melati Sukmawati, "Analisa dan Perancangan Sistem Informasi Pengiriman Barang PT. Media Indra Buana," J. Ilm. Fak. Tek. LIMIT"S, vol. 14, no. 1, pp. 1-12, 2018.

[12] H. Suryotrisongko, "Arsitektur Microservice untuk Resiliensi Sistem Informasi," Sisfo, vol. 06, no. 02, pp. 231-246, 2017, doi: 10.24089/j.sisfo.2017.01.006.

[13] H.- Suryotrisongko and P. K. Farista Ananto, "The Potential of Microservice Architecture for Internet of Things (IoT) in Smart City, a Literature Review," Kursor, vol. 9, no. 1, pp. 9-14, 2017 , doi: 10.28961/kursor.v9i1.95.

[14] H. Yuliansyah, "Perancangan Replikasi Basis Data MySQL dengan Mekanisme Pengamanan Menggunakan SSL Encryption,” J. Inform., vol. 8, no. 1, pp. 826-836, 2014.

[15] Direktorat Jenderal Pembelajaran dan Kemahasiswaan, "Buku Pedoman PKM.” Jakarta, 2020 